\title{
Functionality, Emotion, and Acceptance of Artificial Intelligence Virtual Assistants:
} The Moderating Effect of Social Norms

\author{
Xiaomin Du, Yingkou Institute of Technology, China \\ Xinran Zhao, Dalian University of Technology, China \\ Chia-Huei Wu, Minghsin University of Science and Technology, Taiwan \\ Kesha Feng, Dalian University of Technology, China
}

\begin{abstract}
This paper aims to expand the acceptance of the AI virtual assistant model from the perspective of user cognition. Based on the 240 samples, the authors used multi-layer regression analysis to investigate the influencing factors and differential effects of user acceptance of AI virtual assistant. The results show that functional cognition and emotional cognition of users are important influencing factors for an artificial intelligence virtual assistant. This provides a new perspective for user acceptance processes of the AI virtual assistant. They also examined the moderating effect of social norms between user cognition and AI virtual assistant. At last, a new AI acceptance model of AI virtual assistant was established.
\end{abstract}

\section{KEYWORDS}

Artificial Intelligence, Cognition, Social Norms, Virtual Assistant

\section{INTRODUCTION}

The AI virtual assistants are a series of applications or platforms based on AI technology. They use natural language in both written and oral forms to help people find information and make decisions. The AI virtual assistants (for example, Siri for Apple, Alexa for Amazon Echo, Cortana for Microsoft, etc.) can provide users with convenience and more efficient services (Doorn et al., 2017). Consequently, the frequent use of the AI virtual assistants gradually increases. Among these, AVA as a key variable reflects the extent to which the AI virtual assistants are accepted by users (Fernandes \& Oliveira, 2020). Therefore, it is important to examine the factors affecting the AVA and their differences. There is also much value in making recommendations for product development and private investors.

Currently, the research on the AI virtual assistants is rising, but there are still some gaps. The gaps consist primarily of the following three areas. First, the AI virtual assistants pay little attention to the driver of AI technology from the perspective of user perception. Past advances have focused on the technology itself, changing or replacing everyday manual tasks (Ostrom et al., 2019). Second, previous studies rarely explore the unique empathy characteristics of AI technology (Lin et al., 2019), and lack the different studies on AVA at the level of user emotional cognition (Fernandes \& Oliveira, 2020). Third, previous studies have added social factors as the driving factors of AVA into the service 
robot acceptance model (Wirtz, 2018), but less attention has been paid to the interaction between functional cognition, emotional cognition, and social factors (Fernandes \& Oliveira, 2020). Exploring the interaction effects of different factors is key to broaden application boundary of the AVA model.

On this basis, this research performs three tasks. First, we explore the drivers for AVA from a user perception perspective. We consider functional cognition and emotional cognition as the major factors which influences AVA, in the hope of bridging the gap on user perception. Second, we investigate the empathy traits of artificial intelligence technology. Referring to the service robot acceptance model (Wirtz et al., 2018), we divide emotional cognition into three dimensions (perceived social presence, perceived social interactions and perceived humanness) to explore the influence of user emotional cognition based on empathy. Lastly, we present external social norms as factors in social relations. In fact, these social factors are important, especially the spread of innovative technological products such as the AI virtual assistants (Yoo et al., 2021). We explore the interaction of social norms between two types of user perception and AVA, and establish a social regulatory framework.

There are three main conclusions to be drawn from this research. First, AVA is positively influenced by user motivation, and it depends mainly on the utilitarian motivation of functional cognition. Secondly, this research examines the positive relationship between emotional cognition and AVA in terms of AI empathy characteristics. Among the three dimensions of emotional cognition, perceived social presence and perceived social interactivity have been shown to have significant positive effects. And the perceived humanness shows a non-linear inverted U-shaped relation to AVA. Finally, this research finds that social norms as a positive conditioning variable facilitate the roles of functional cognition and emotional cognition on AVA. In this study, the AVA model is developed and refined from the perspective of user perception, extend the model of technology acceptance and service robot acceptance. At the same time, the model incorporates a moderating mechanism from outside society, which has good implications for the design, investment, and practical use of AI technologies and AI applications.

\section{RESEARCH FRAMEWORK AND HYPOTHESIS DEVELOPMENT}

Previous studies have mainly focused on the technology acceptance models. The technology acceptance model is driven by its perceived usefulness and perceived of ease of use. It has been criticized for being simplistic due to its simplicity of construction (Fernandes \& Pedroso, 2017). Subsequent models of technological acceptance have extended social factors and hedonic values (Venkatesh, 2000; Venkatesh et al., 2003). The service robot acceptance model (Wirtz, 2018) added social emotion and relationship variables as its determinants based on the technology acceptance model, and examined consumer perceptions, beliefs and behavioral intentions related to the services provided by robots. However, these models are only used to study the factors of a single technology product, which has limitations and cannot fully explain the artificial intelligence virtual assistants and other similar products.

In these models, some variables are similar from one model to another (e.g., perceived usefulness and performance expectations, perceived ease of use and expected workload, social norms and social factors). However, previous studies have yet to reach an objective consensus on which model performs best in each domain (Sohn \& Kwon, 2019). Therefore, this does not fully explain AVA. This research analyzes, classifies, and summarizes the variables based on the technology acceptance model, the service robot acceptance model and related theories. It is found that the process of user acceptance is influenced by functional cognition and emotional cognition, and social norms become an important regulating factor of AVA. Therefore, this research discusses the artificial intelligence virtual assistants and constructs the following model (Figure 1).

\subsection{Functional Cognition: Perceived Usefulness and Perceived Ease of Use}

Previous research has mostly used the technology acceptance model (Davis, 1989; Davis et al., 1992) and associated models as a theoretical basis. The technology acceptance model was developed 


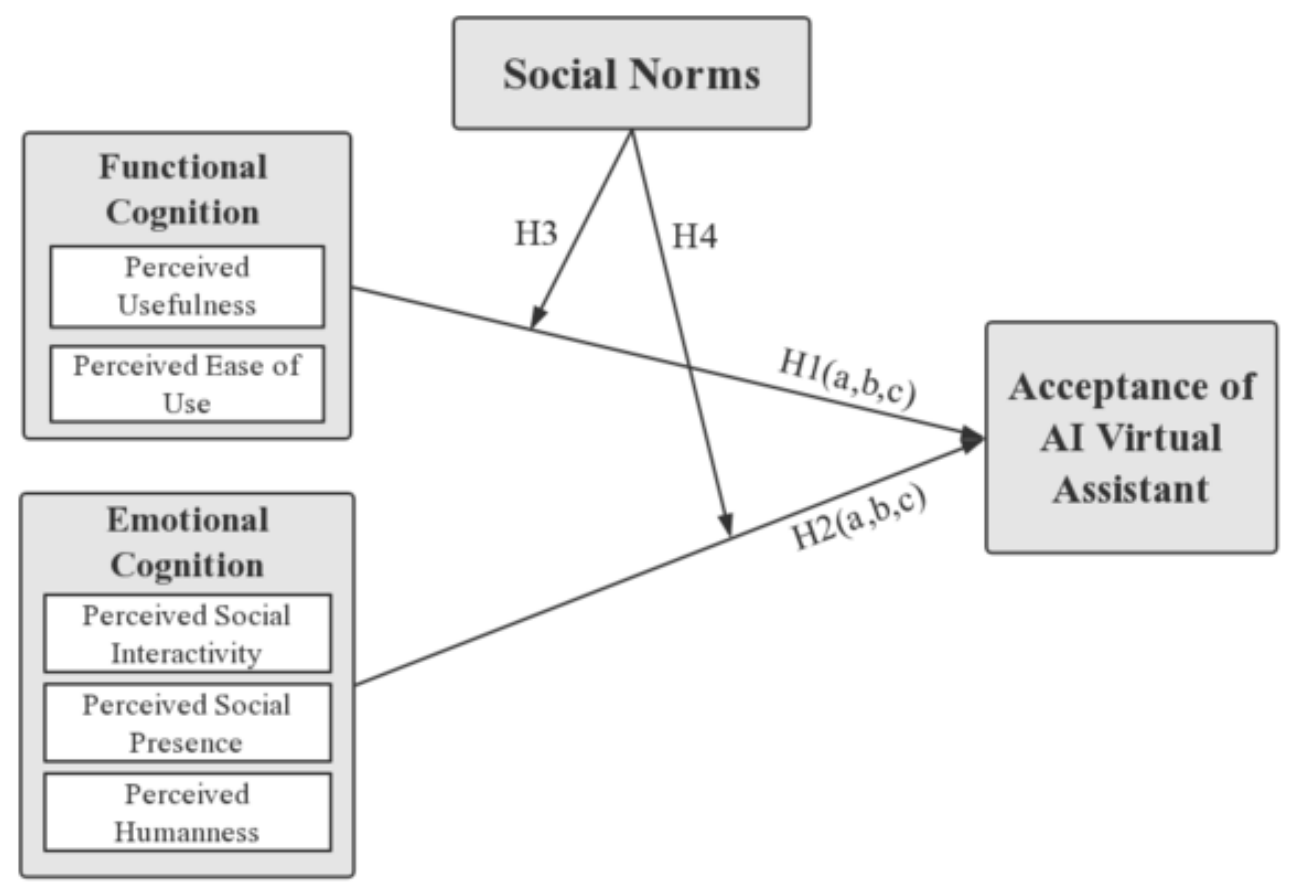

based on the Theory of Reasoned Action (TRA). It is often used to examine variables that influence consumers' intentions to use technology products and services (Fernandes \& Pedroso, 2017). It aims to improve the understanding of the AVA information system (Davis, 1989; Davis et al., 1992). This widely used model (Lee et al., 2003) basically contains two components: perceived usefulness and perceived of ease of use.

The AI virtual assistant is a typical application of AI technology in people's daily lives. In the technology acceptance model's view, AVA is motivated by perceived usefulness and perceived of ease of use. Perceived usefulness and perceived of ease of use refer to the extent to which an individual perceives a technology to enhance its performance and the extent to which using technology requires minimal physical and mental input, respectively (Davis, 1989). When robots are used as social assistants, perceived usefulness and perceived of ease of use represent a user's functional acceptance of the AI virtual assistants. This is the core of assessing the AVA domain (Heerink et al., 2010), illustrating the functional goals of using the new technology (Lu, 2020). Thus, perceived usefulness and perceived of ease of use as functional cognition influence AVA. Therefore, we put forward this hypothesis.

H1: Functional cognition (H1a: perceived usefulness; H1b: perceived of ease of use) positively affects AVA.

Utility refers to the degree to which the use of technology can enhance the performance of a user's task (Davis et al., 1989). This is an important consideration in determining the user acceptance, adoption, and use of the AI virtual assistants (Kulviwat et al., 2007; Law et al., 2018). In previous studies, perceived usefulness was considered as the strongest predictor of behavioral intention to use 
new technologies (e.g., Compeau et al., 1999; Venkatesh, 2000; Venkatesh et al., 2003). In today's environment, perceived usefulness is the degree to which service robots can provide consistent and reliable services to users (Gursoy et al., 2019). When the AI virtual assistants deliver front-line services, whether they can provide useful services to users is closely linked to AVA. Therefore, we put forward this hypothesis.

H1a: Perceived usefulness positively affects AVA.

Perceived of ease of use directly assesses the effort involved in using and learning new technologies. This issue has been the subject of extensive research on technology acceptance and adoption (e.g., Venkatesh, 2000; Kulviwat et al., 2007). The theoretical model of AI device use acceptance explains customer behaviors during using AI device. The multistage process adopted by users affects their willingness to accept AI devices during service meetings. The process of interacting with the AI virtual assistants may also lead to communication barriers between customers and AI devices due to the limitations of the level of AI technology (Gursoy et al., 2019). To do this, it takes more knowledge to understand the complex and confusing design of AI devices. And this increased workload and effort often negatively impact users. Conversely, the perceived of ease of use will positively affect AVA. Therefore, we put forward this hypothesis.

H1b: Perceived of ease of use positively affects AVA.

\subsection{Emotional Cognition: Perceived Social Interactivity, Perceived Social Presence, and Perceived Humanness}

Previous studies have pointed out that customer acceptance of robots depends not only on their functional cognition but also on emotional factors (Heerink et al., 2010; Doorn et al., 2017; NG et al., 2021). Wirtz et al. (2018) added three categories of factors to the original technology acceptance model. It includes perceived humanness (Tinwell et al., 2011), perceived social interactivity, and perceived social presence (Doorn et al., 2017). It's the service robot acceptance model that aims to investigate consumer perceptions and behavioral intentions related to the services provided by robots. They argue that service-providing robots may have physical roles (Chattaraman et al., 2019) as well as virtual representations (e.g., invisible conversational agents such as Siri and Alexa). From the perspective of empathy, this research is convenient to study the emotional cognition of users. Empathy can be defined as a combination of emotional response and cognitive understanding of the experiences and feelings of others, and it has both emotional and cognitive components (Corina et al., 2021). In this research, the effects of emotional cognitive factors on AVA are investigated by using perceived social interactivity, perceived social presence, and perceived humanness as variables. Therefore, we propose this hypothesis.

H2: Emotional cognition factors (H2a: perceived social interactivity; H2b: perceived social presence; H2c: perceived humanness) have a positive impact on AVA.

Perceived social interactivity can be defined as the perception that a robot displays appropriate actions and "emotions" according to social norms (Wirtz et al., 2018). The social intelligence of a robot increases its trustworthiness. As AI technology evolves, users may feel they can interact with artificial agents like other people in response to human-like cues such as voice, conversation, and performing traditional human roles (Chattaraman et al., 2019). The language-based communication skills of the AI virtual assistants evoke a sense of sociality that allows users to "treat other people and respond socially" to the artificial agents. The social appeal of the AI virtual assistant's increases when they interact socially, demonstrate social competence, and thus gain trust and help users "behave 
pleasantly" (McLean \& Wilson, 2019), thereby motivating users to use the technology. Therefore, we put forward this hypothesis.

H2a: Perceived social interactivity positively influences AVA.

Social presence is the degree to which people believe that someone is "really there" (Heerink et al., 2008). And it can be described as the degree to which a robot makes individuals feel as if they are present in another social entity (Heerink et al., 2008; [REMOVED HYPERLINK FIELD]Doorn et al., 2017). Perceived social presence refers to a user's perception of an AI virtual assistant as a social object that exists, a warm medium that conveys a sense of human contact, sociability, and sensitivity (Khaled \& Milena, 2007). A, O. F., and B, M. L. (2018) argue that social presence is a key factor in the success of AI bots such as the AI virtual assistants. During interaction with a robot, the user's subjective perception that the robot does "exist" (Wirtz et al., 2018) influences the way it is perceived and received (Qiu et al., 2020). Perceived social presence has been shown to affect trust-building, as individuals are more likely to build trust in others when meeting them, and thus perceived social presence or "being taken care of" affects AVA. Therefore, we put forward this hypothesis.

H2b: Perceived social presence has a positive impact on AVA.

Perceived humanness refers to the type of emotions that users experience when using a product (Velez \& Jentsch, 2016). At this point, products tend to have human characteristics, including psychological characteristics (emotion, personality, gestures, etc.) and non-psychological characteristics (such as entities like the human body). The AI virtual assistants studied in this research (e.g., Siri, etc.) have no human-like entities, reside on cell phones, stereos, TVs, etc., and usually do not have non-psychological features, but rather focus more on the influence produced by their perceived humanness psychological features. Previous research has shown that perceived humanness is crucial for understanding the roles of human-technology interactions, especially in the context of AI and service robots ([REMOVED HYPERLINK FIELD]Doorn et al., 2017). The AI virtual assistants resemble humans by learning to mimic human behaviors in terms of language, operations, etc., and positive emotions that humans generate. Therefore, we put forward this hypothesis.

H2c: Perceived humanness has a positive impact on AVA.

\subsection{Social Norms}

Social norms show the personal perceptions of the behaviors that people consider important to him/her and reflect the degree to which an individual feels influenced by the group around him/her. According to previous literature, social norms refer to the extent to which a user's social group considers the use of virtual assistants to provide services as relevant and in line with social norms.

Social impact theory (Latane, 1981) holds that people will follow social norms if groups are important to them. People's decisions often depend not only on their perceptions and information but also on the behaviors of those around them (Vedadi \& Greer, 2021). At the same time, social impact theory points out that when individuals perceive the existence of others, no matter whether the existence is real or virtual, the influence of others on us is objective. The AI virtual assistant meet this condition, so the norms and attitudes of a user's social group are often the key determinants of an individual's behavioral intentions (Rather, 2018), and social norms will influence AVA. The findings show that users tend to adopt the culture, values, and norms of their social group as their habits, making behavioral decisions accordingly (Jeon et al., 2018; Wang et al., 2021). When a user's social group (e.g., friends, colleagues, family members) perceives the use of an AI virtual assistant as useful or easy to use and suggests it to the user, such positive attitudes and values of the community 
play a role in the user's decision to support the AI virtual assistant, thus positively contributing to AVA. Therefore, we put forward this hypothesis.

H3: Social norms positively contribute to the impact of functional cognition on user AVA.

The anthropomorphic behaviors of the AI virtual assistants when interacting with users (e.g., language-based communication) evoke a sense of sociality (Uddin et al., 2021). It leads the users to treat the AI assistants as they treat others and respond to them socially, promoting a sense of social presence and social interaction. Social response theory suggests that human interactions with the AI virtual assistants apply to social norms (Nass \& Moon, 2000; Reeves \& Nass, 1996) in response to social cues (e.g., conversations), building a social model (Breazeal, 2003). At the same time, perceived humanness enhances this social orientation when interacting (Nass et al., 2010). Due to the influence of social norms, users internalize them to make decisions (Jeon et al., 2018; Thompson et al., 1991). These internalized social norms influence users' behavioral decisions, prompting positive emotions and social connections in using the AI virtual assistants and increasing AVA. Users, influenced by the social norms, believe that using AI virtual assistants' behaviors needs to conform to the community's habits and perceptions. Therefore, we put forward this hypothesis.

H4: Social norms positively contribute to the influence of emotional cognition factors on AVA.

\section{DATA AND RESEARCH METHODS}

\subsection{Scale Design and Data Sources}

This research collects the sample data with the help of the questionnaire star platform, using QQ, WeChat, WEIBO, and other channels to send questionnaires, a total of 240 valid questionnaires, the sample descriptive statistics results are shown in Table 1.

\subsection{Variable Measurement}

The research scale selects mature items of the measurement scale, which effectively guarantees the reliability and validity of the measurement scale, meeting the needs of the research. Based on the technology acceptance model (Venkatesh \& Davis, 2000) according to the characteristics of the AI virtual assistants and the research results of Kwonsang Sohn et al. (2020), functional cognition is divided into two dimensions of perceived usefulness and perceived of ease of use, each of which contained four questions. Based on the service robot acceptance model, emotional cognition is divided into three dimensions: perceived social interactivity, perceived social presence and perceived humanness. From the study by Dogan Gursoy (2019), four questions were set in the dimension of perceived humanness. Perceived social interactivity contains two items and perceived social presence contains three items, which are from the study in Fernandes et al. (2020). Social norms refer to the research of Kwonsang Sohn et al. (2020) and contain four questions. According to the research by Fernandes \& Oliveira (2020), AVA contains three question projects. The items in question are rated on a 5 -scale Likert scale, with 1-5 indicating very poor to complete agreement.

\subsection{Reliability Test}

First, the descriptive statistics and correlation coefficients are shown in Table 2, and the seven variables do not have covariance characteristics. In this research, we use correlation analysis to investigate the correlation between perceived usefulness, perceived of ease of use, perceived humanness, perceived social interaction, perceived social presence, social norms, and AVA. The results show that all of them show significance with correlation coefficient values of $0.666,0.722,0.427,0.638,0.641,0.807$, 
Table 1. Results of descriptive statistics of the sample ( $N=240$ )

\begin{tabular}{|c|c|c|c|}
\hline Content & Category & Sample size & Proportion (\%) \\
\hline \multirow{2}{*}{ Gender } & Male & 101 & 42.08 \\
\hline & Female & 139 & 57.92 \\
\hline \multirow{6}{*}{ Age } & Under 20 years old & 36 & 15 \\
\hline & 21-25 years old & 111 & 46.25 \\
\hline & 26-30 years old & 32 & 13.33 \\
\hline & 31-35 years old & 27 & 11.25 \\
\hline & $36-40$ years old & 13 & 5.42 \\
\hline & Over 41 years old & 21 & 8.75 \\
\hline \multirow{4}{*}{ Education } & Undergraduate & 152 & 63.33 \\
\hline & Master & 37 & 15.42 \\
\hline & $\mathrm{PhD}$ & 8 & 3.33 \\
\hline & Others & 43 & 17.92 \\
\hline \multirow{3}{*}{ Marital Status } & Unmarried & 153 & 63.75 \\
\hline & Married with child & 70 & 29.17 \\
\hline & Married with no child & 17 & 7.08 \\
\hline
\end{tabular}

Table 2. Descriptive statistics results and correlation coefficients

\begin{tabular}{|c|c|c|c|c|c|c|c|c|c|}
\hline & $\begin{array}{l}\text { Average } \\
\text { Value }\end{array}$ & $\begin{array}{c}\text { Standard } \\
\text { Deviation }\end{array}$ & 1 & 2 & 3 & 4 & 5 & 6 & 7 \\
\hline $\begin{array}{l}\text { Perceived } \\
\text { Usefulness }\end{array}$ & 3.654 & 0.704 & 1 & & & & & & \\
\hline $\begin{array}{l}\text { Perceived } \\
\text { of Ease of } \\
\text { Use }\end{array}$ & 3.623 & 0.799 & $0.765^{* *}$ & 1 & & & & & \\
\hline $\begin{array}{l}\text { Perceiving } \\
\text { Humanness }\end{array}$ & 2.958 & 0.891 & $0.230^{* *}$ & $0.342 * *$ & 1 & & & & \\
\hline $\begin{array}{l}\quad \text { Perceptual } \\
\text { Social } \\
\text { Interaction }\end{array}$ & 3.479 & 0.992 & $0.513^{* *}$ & $0.553 * *$ & $0.326^{* * *}$ & 1 & & & \\
\hline $\begin{array}{l}\quad \text { Perceiving } \\
\text { Social } \\
\text { Presence }\end{array}$ & 3.408 & 1.074 & $0.513^{* *}$ & $0.578^{* * *}$ & $0.397 * *$ & $0.688^{* * *}$ & 1 & & \\
\hline $\begin{array}{l}\text { Social } \\
\text { Norms }\end{array}$ & 3.046 & 1.141 & $0.460^{* *}$ & $0.451^{* *}$ & 0.122 & $0.363^{* *}$ & $0.327 * *$ & 1 & \\
\hline AVA & 2.718 & 1.032 & $0.666^{* * *}$ & $0.722 * *$ & $0.427 * *$ & $0.638^{* *}$ & 0.641 ** & $0.807^{* * *}$ & 1 \\
\hline
\end{tabular}


Table 3. Confidence test results

\begin{tabular}{|l|l|l|}
\hline Variables & Number of items & Cronbach alpha \\
\hline Perceived of Ease of Use & 4 & 0.844 \\
\hline Perceived Usefulness & 4 & 0.906 \\
\hline Perceiving Humanness & 4 & 0.918 \\
\hline Perceptual Social Interaction & 2 & 0.845 \\
\hline Perceiving Social Presence & 3 & 0.935 \\
\hline Social Norms & 4 & 0.950 \\
\hline AVA & 3 & 0.920 \\
\hline
\end{tabular}

and the correlation coefficient values are all greater than 0 . This means that they all have positive correlations with AVA.

Next, we conduct a reliability test. The results of the reliability test are shown in Table 3 . The data involved 7 dimensions, namely, perceived usefulness, perceived of ease of use, perceived humanness, perceived social interaction, perceived social presence, social norms, and AVA; the Cronbach alpha coefficient is used to measure the quality level of reliability of the data. The Alpha coefficient above 0.8 indicates high reliability. It indicates good reliability between 0.7 and 0.8 , and acceptable reliability between 0.6 and 0.7. When it is less than 0.6, the reliability is poor. From Table 3, the $\alpha$ coefficient values of these seven dimensions are higher than 0.7 , and the minimum is 0.844 , thus indicating that the reliability quality level of this data is good, and the research data are true and reliable.

Then, we conduct a validity test, the results of which are shown in Table 4 . The scale of this study is represented by a total of 7 factors. Table 4 shows that the 7 factors correspond to a total of 24 measures, and the standardized loading coefficient value for no measure is less than 0.7 , thus synthetically indicating excellent convergent validity of the scale data in this study.

Finally, we also perform KMO and Bartlett's test. As can be seen from Table 5: The KMO value is $0.935>0.6$, indicating that most of the information on the question items can be extracted from the seven dimensions. Thus, the combination indicates that the study data has a good level of structural validity.

\section{EMPIRICAL TEST AND ANALYSIS}

\subsection{Correlation Test}

This research uses SPSS software and multilevel regression analysis for hypothesis testing. This hierarchical regression analysis involves a total of three models. The independent variables in model 1 are control variables (gender, age, education, and marital status). Model 2 adds perceived of ease of use, perceived usefulness to model 1 . Model 3 adds perceived humanness, the square of perceived humanness, perceived social interactivity, perceived social presence to model 2 . And the dependent variable of the model is AVA. The results of data processing are shown in Table 6 .

From the above table, gender, age, educational background, and marital status are used as independent variables, while AVA is used as the dependent variable for linear regression analysis. And from the above table, the model R-squared value is 0.016 , which means that gender, age, educational background, and marital status can explain the AVA by $1.6 \%$ of the variation. When the F-test is performed on the model, it is found that the model did not pass the F-test $(\mathrm{F}=0.940, \mathrm{p}>0.05)$. It means that gender, age, educational background, and marital status do not have an influence on AVA. Therefore, the influence of the independent variables on the dependent variable cannot be specifically analyzed. 


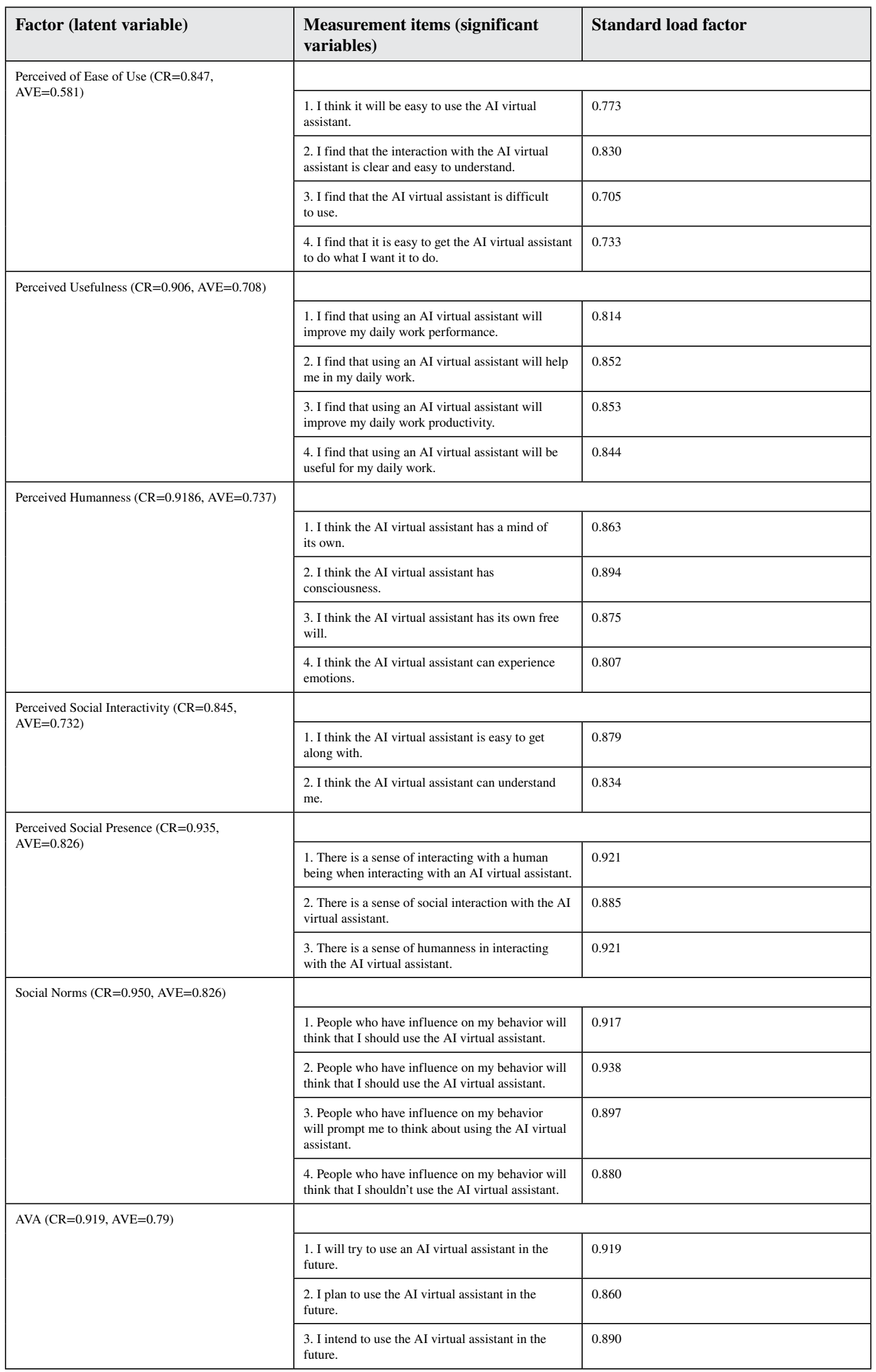


Table 5. KMO and Bartlett's test

\begin{tabular}{|l|l|l|}
\hline \multicolumn{2}{|l|}{ KMO Value } & $\mathbf{0 . 9 3 5}$ \\
\hline \multirow{3}{*}{ Bartlett Sphericity Test } & Approximate Cardinality & 5290.278 \\
\cline { 2 - 3 } & df & 276 \\
\cline { 2 - 3 } & P-Value & 0.000 \\
\hline
\end{tabular}

For model 2: its change in F-value after adding perceived of ease of use, perceived usefulness to model 1 shows significance $(\mathrm{p}<0.05)$, implying that the addition of perceived of ease of use, perceived usefulness has explanatory significance for the model. In addition, the R-squared value increases from 0.016 to 0.470 , implying that perceived of ease of use, perceived usefulness can have an explanatory strength of $45.4 \%$ on AVA. Specifically, the regression coefficient value for perceived of ease of use is 0.332 and shows significance $(t=4.216, p=0.000<0.01)$, implying that perceived of ease of use would have a positive effect on AVA. The regression coefficient value of perceived usefulness is

Table 6. Multilevel regression test results (Explanatory variable: AVA)

\begin{tabular}{|c|c|c|c|c|}
\hline Category & Variable & Model 1 & Model 2 & Model 3 \\
\hline \multirow[t]{4}{*}{ Control Variables } & Gender & $\begin{array}{l}-0.010 \\
(-0.073)\end{array}$ & $-0.031(-0.348)$ & $0.048(0.603)$ \\
\hline & Age & $0.025(0.452)$ & $0.035(0.949)$ & $0.024(0.727)$ \\
\hline & Education & $0.106(1.564)$ & $0.053(1.167)$ & $0.045(1.114)$ \\
\hline & Marital Status & $0.248(1.901)$ & $0.136(1.540)$ & $0.072(0.908)$ \\
\hline \multirow[t]{6}{*}{ Explanatory Variables } & $\begin{array}{l}\text { Perceived of Ease } \\
\text { of Use }\end{array}$ & & $0.422 * *(4.294)$ & $0.335 * *(3.767)$ \\
\hline & $\begin{array}{l}\text { Perceived } \\
\text { Usefulness }\end{array}$ & & $0.625 * *(7.190)$ & $0.362 * *(4.352)$ \\
\hline & $\begin{array}{l}\text { Perceived } \\
\text { Humanness }\end{array}$ & & & $0.653 * *(2.811)$ \\
\hline & $\begin{array}{c}\text { Perceived } \\
\text { Humanness Squared }\end{array}$ & & & $-0.079 *(-2.166)$ \\
\hline & $\begin{array}{l}\text { Perceived Social } \\
\text { Interactivity }\end{array}$ & & & $0.214 * *(3.761)$ \\
\hline & $\begin{array}{l}\text { Perceived Social } \\
\text { Presence }\end{array}$ & & & $0.118 *(2.119)$ \\
\hline \multirow{5}{*}{$\begin{array}{l}\text { Model Explanatory } \\
\text { Degree }\end{array}$} & $\mathrm{R}^{2}$ & 0.05 & 0.572 & 0.672 \\
\hline & Adjusted $\mathrm{R}^{2}$ & 0.034 & 0.561 & 0.657 \\
\hline & F Value & $\begin{array}{c}\mathrm{F}(4,235) \\
=3.071, \mathrm{p}=0.017\end{array}$ & $\begin{array}{c}\mathrm{F}(6,233) \\
=51.913, \mathrm{p}=0.000\end{array}$ & $\begin{array}{c}\mathrm{F}(10,229) \\
=46.848, \mathrm{p}=0.000\end{array}$ \\
\hline & $\triangle R^{2}$ & 0.05 & 0.522 & 0.1 \\
\hline & $\triangle F$ Value & $\begin{array}{c}\mathrm{F}(4,235) \\
=3.071, \mathrm{p}=0.017\end{array}$ & $\begin{array}{c}F(2,233) \\
=142.214, p=0.000\end{array}$ & $\begin{array}{c}\mathrm{F}(4,229) \\
=17.369, \mathrm{p}=0.000\end{array}$ \\
\hline
\end{tabular}


0.378 and shows significance $(t=5.430, p=0.000<0.01)$, implying that perceived usefulness would have a significant positive influence relationship on AVA.

The regression coefficient value for perceived usefulness is 0.378 and shows significance $(\mathrm{t}=5.430, \mathrm{p}=0.000<0.01)$, implying that perceived usefulness would have a significant positive relationship on AVA. In this research, Figure 2 shows the significant impact of functional cognition (perceived usefulness and perceived of ease of use).

Figure 2. The relationship between functional cognition (perceived usefulness, perceived of ease of use) and AVA

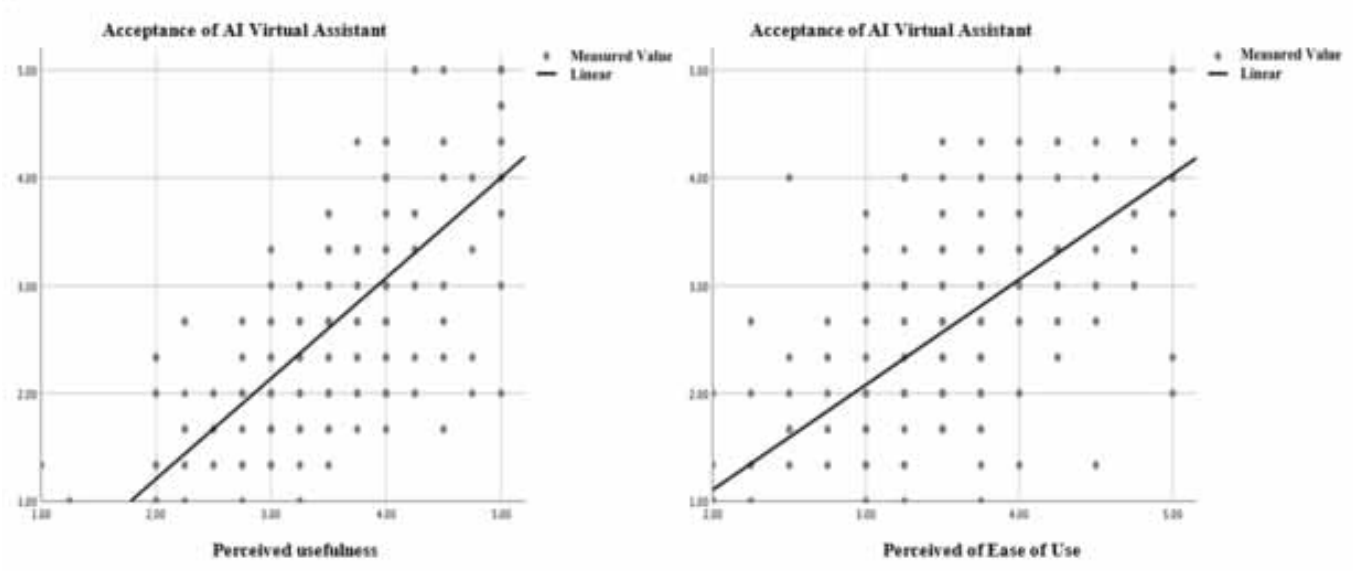

For model 3: its change in $\mathrm{F}$ value after adding perceived humanness, the square of perceived humanness, perceived social interactivity, perceived social presence to model 2 shows significance $(\mathrm{p}<0.05)$, implying that the addition of these has explanatory significance for the model. In addition, the R-squared value increased from 0.470 to 0.589 , implying that these can have a significant effect on AVA with an explanatory strength of $12.0 \%$. Specifically, the regression coefficient value of perceived humanness is 0.772 and shows significance $(t=4.123, p=0.000<0.01)$, implying that perceived humanness would have a significant positive influence relationship.

The regression coefficient value of the square of perceived humanness is -0.140 and shows significance $(\mathrm{t}=-4.713, \mathrm{p}=0.000<0.01)$, implying that the square of perceived humanness has a significant effect on AVA. In this research, the nonlinear relationship of perceived humanness can be seen in Figure 3.

In conclusion, functional cognition generates $45.4 \%$ explanatory power for AVA, and emotional cognition generates $12.0 \%$ explanatory power. Functional cognition is the core driving factor of AVA.

Figure 4 below demonstrates the strong link between emotional cognition (perceived social interactivity, perceived social presence) and AVA. The regression coefficient value for perceived social interactivity is 0.140 and shows significance $(\mathrm{t}=2.158, \mathrm{p}=0.032<0.05)$, implying that perceived social interactivity would have a significant effect on AVA. The regression coefficient value for perceived social presence is 0.143 and shows significance $(t=2.766, p=0.006<0.01)$, implying that perceived social presence would have a significant effect on AVA. 
Figure 3. The nonlinear relationship between perceived humanness and AVA

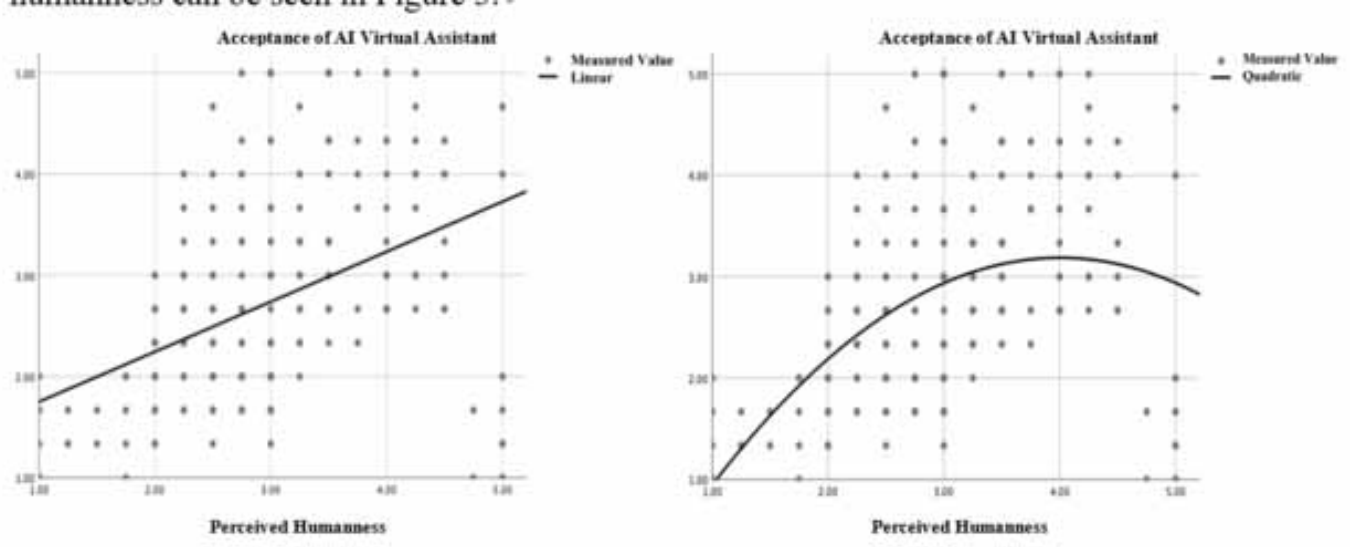

Figure 4. The relationship between emotional cognition (perceived social interactivity, perceived social presence) and AVA
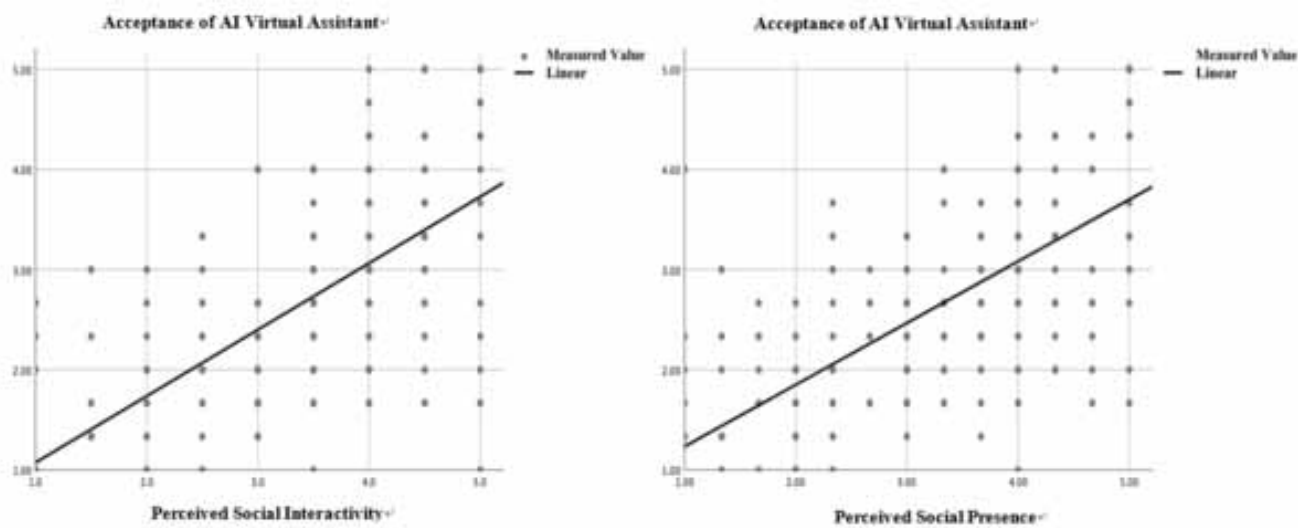

\subsection{Moderating Effect Test}

\subsubsection{Social Norms and Functional Cognition}

As can be seen from Table 7, the moderating effect is divided into three models, model 1 includes the independent variable (functional cognition). Model 2 adds the moderating variable (social norms) to model 1 . And model 3 adds the interaction term (the product of the independent variable and the moderating variable) to model 2.

The purpose of model 1 is to investigate the effect of the independent variable (functional cognition) on the dependent variable (AVA) without considering the interference of the moderating variable (social norms). The table above shows that the independent variable (functional cognition) shows significance $(\mathrm{t}=16.990, \mathrm{p}=0.000<0.05)$. Functional cognition has a significant effect relationship on AVA.

The moderating effect can be viewed in two ways, the first is to view the significance of the change in F-value when going from model 2 to model 3, and the second is to view the significance of the interaction term in model 3 , and this time the moderating effect is analyzed in the second way.

As shown in Table 7 above, the interaction term between functional cognition and social norms shows significance $(\mathrm{t}=3.752, \mathrm{p}=0.000<0.05)$. With the help of the slope coefficient table (Table 8$)$ 
Table 7. Results of the analysis of moderating effects (explanatory variable: AVA, independent variable: functional cognition)

\begin{tabular}{|c|c|c|c|}
\hline & Model 1 & Model 2 & Model 3 \\
\hline Constants & $2.718 * *(60.550)$ & $2.718 * *(93.259)$ & $2.671 * *(85.949)$ \\
\hline $\begin{array}{l}\text { Functional } \\
\text { Cognition }\end{array}$ & $1.082 * *(16.990)$ & $0.668 * *(14.127)$ & $0.646^{* *}(13.928)$ \\
\hline Social Norms & & $0.529 * *(18.099)$ & $0.514 * *(17.836)$ \\
\hline $\begin{array}{l}\text { Functional } \\
\text { Cognition* Social } \\
\text { Norms }\end{array}$ & & & $0.122 * *(3.752)$ \\
\hline Sample Size & 240 & 240 & 240 \\
\hline $\mathrm{R}^{2}$ & 0.548 & 0.810 & 0.821 \\
\hline Adjustment $\mathrm{R}^{2}$ & 0.546 & 0.809 & 0.819 \\
\hline F Value & $\begin{aligned} & F(1,238)=288.647 \\
p= & 0.000\end{aligned}$ & $\begin{aligned} \mathrm{F}(2,237)=506.156 \\
\mathrm{p}=0.000\end{aligned}$ & $\begin{aligned} & F(3,236)=360.750, \\
& p=0.000\end{aligned}$ \\
\hline$\triangle R^{2}$ & 0.548 & 0.262 & 0.011 \\
\hline$\triangle F$ Value & $\begin{aligned} & F(1,238)=288.647 \\
p= & 0.000\end{aligned}$ & $\begin{aligned} & F(1,237)=327.583 \\
p= & 0.000\end{aligned}$ & $\begin{aligned} & F(1,236)=14.078, \\
p= & 0.000\end{aligned}$ \\
\hline
\end{tabular}

Table 8. Simple slope analysis (independent variable: functional cognition)

\begin{tabular}{|l|c|c|c|r|r|r|}
\hline $\begin{array}{c}\text { Adjustment of Variable } \\
\text { Levels }\end{array}$ & $\begin{array}{c}\text { Regression } \\
\text { Coefficient }\end{array}$ & $\begin{array}{c}\text { Standard } \\
\text { Error }\end{array}$ & T & \multicolumn{2}{|c|}{ P } & \multicolumn{2}{|c|}{$95 \%$ CI } \\
\hline Average Value & 0.646 & 0.046 & 13.928 & 0.000 & 0.555 & 0.737 \\
\hline High Level (+1SD) & 0.785 & 0.056 & 14.103 & 0.000 & 0.676 & 0.894 \\
\hline Low Level (-1SD) & 0.506 & 0.063 & 8.044 & 0.000 & 0.383 & 0.630 \\
\hline
\end{tabular}

Figure 5. Simple slope graphs (based on functional cognition)

\section{Simple Slope Graphs (Based on Functional Cogintion)}
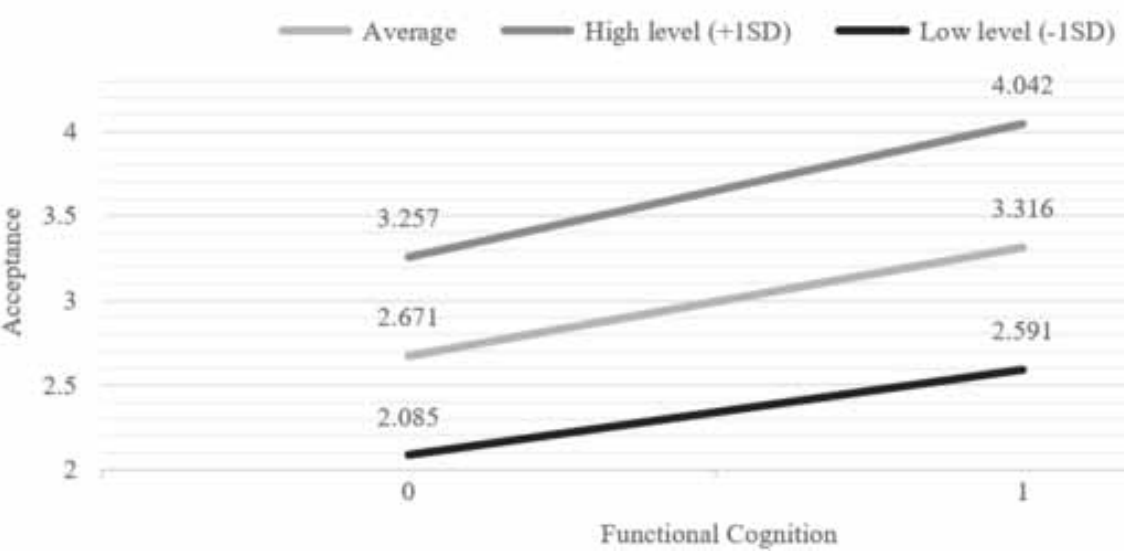
that follows, the degree of the influence of the moderating variable (social norms) on the AVA differs significantly at different levels.

The level of adjustment variables in Table 8 corresponds to the three lines in Figure 5. The three levels of the moderating variable are average value, high level (average value plus 1 standard deviation) and low level (average value plus minus 1 standard deviation). And the regression coefficient in Table 8 corresponds to the slope in Figure 5, which intuitively shows the difference in the influence of social norms under different functional cognition levels. Figure 5 visualizes the difference in the magnitude (slope) of the effect of the independent variable (functional cognition) on the dependent variable (AVA) at different levels of the moderating variable (social norms), i.e., the specific moderating effect.

Table 9. Results of the analysis of moderating effects (explanatory variable: AVA, independent variable: emotional cognition)

\begin{tabular}{|c|c|c|c|}
\hline & Model 1 & Model 2 & Model 3 \\
\hline Constants & $\begin{array}{l}2.718^{* *} \\
(57.878)\end{array}$ & $\begin{array}{c}2.718^{* *} \\
(110.376)\end{array}$ & $\begin{array}{c}2.681^{* *} \\
(108.267)\end{array}$ \\
\hline $\begin{array}{l}\text { Emotional } \\
\text { Cognition }\end{array}$ & $\begin{array}{l}0.920 * * \\
(15.595)\end{array}$ & $\begin{array}{l}0.637 * * \\
(19.353)\end{array}$ & $\begin{array}{l}0.622^{* *} \\
(19.686)\end{array}$ \\
\hline $\begin{array}{l}\text { Social } \\
\text { Norms }\end{array}$ & & $\begin{array}{l}0.577 * * \\
(25.071)\end{array}$ & $\begin{array}{l}0.557 * * \\
(24.839)\end{array}$ \\
\hline $\begin{array}{l}\quad \text { Emotional } \\
\text { Cognition * } \\
\text { Social Norms }\end{array}$ & & & $\begin{array}{l}0.120^{* * *} \\
(4.837)\end{array}$ \\
\hline $\begin{array}{l}\text { Sample } \\
\text { Size }\end{array}$ & 240 & 240 & 240 \\
\hline $\mathrm{R}^{2}$ & 0.505 & 0.865 & 0.877 \\
\hline $\mathrm{R}^{2}$ Adjustment & 0.503 & 0.863 & 0.875 \\
\hline F Value & $\begin{array}{c}\mathrm{F}(1,238)=243.199, \\
\mathrm{p}=0.000\end{array}$ & $\mathrm{~F}(2,237)=756.507, \mathrm{p}=0.000$ & $\mathrm{~F}(3,236)=559.803, \mathrm{p}=0.000$ \\
\hline$\triangle R^{2}$ & 0.505 & 0.359 & 0.012 \\
\hline$\triangle F$ Value & $\begin{aligned} & F(1,238)=243.199, \\
& p=0.000\end{aligned}$ & $\mathrm{~F}(1,237)=628.553, \mathrm{p}=0.000$ & $\mathrm{~F}(1,236)=23.399, \mathrm{p}=0.000$ \\
\hline
\end{tabular}

\subsubsection{Social Norms and Emotional Cognition}

As can be seen from Table 9, the moderating effect is divided into three models, model 1 includes the independent variable (emotional cognition). Model 2 includes the moderating variable (social norms) based on model 1. And model 3 includes the interaction term (product term of the independent variable and the moderating variable) based on model 2.

For model 1, the aim is to investigate the effect of the independent variable (emotional cognition) on the dependent variable (AVA) when the interference of the moderating variable (social norms) is not considered. As can be seen from the above table, the independent variable (emotional cognition) shows significance $(\mathrm{t}=15.595, \mathrm{p}=0.000<0.05)$. It means that emotional cognition has a significant influence relationship on AVA. 
Figure 6. Simple Slope Graphs (Based On Emotional Cognition).

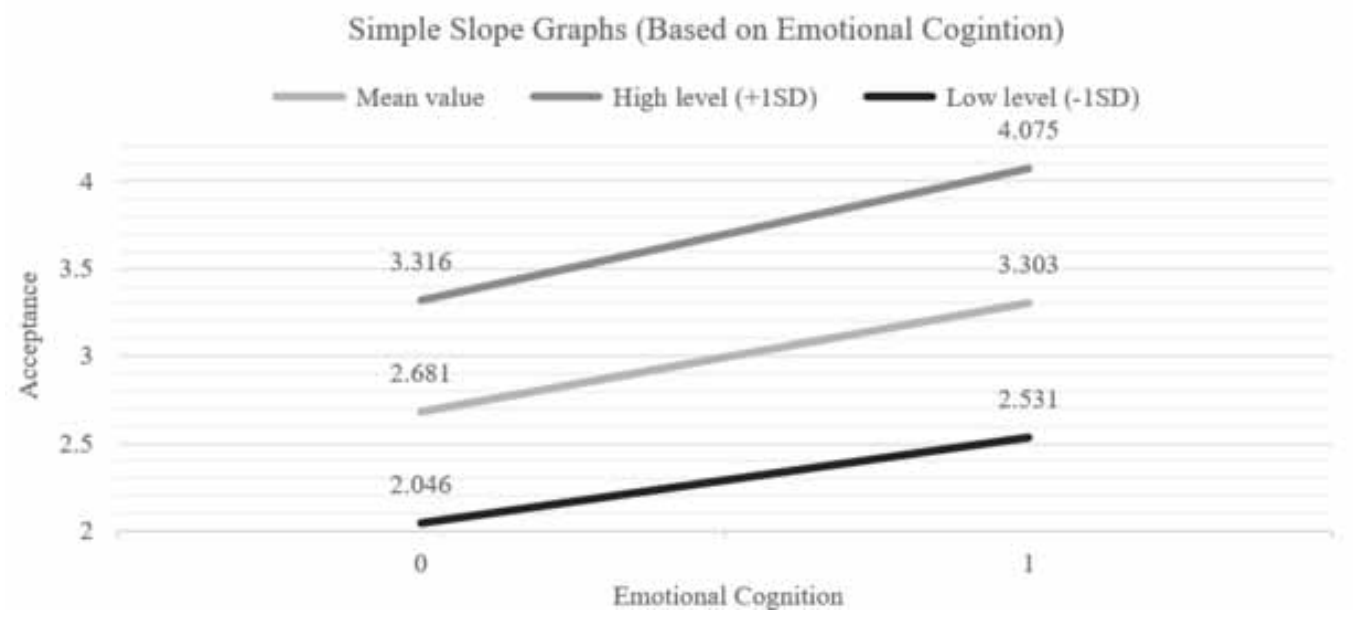

The moderation effect can be viewed in two ways, the first is to view the significance of the change in F-value when going from model 2 to model 3; the second is to view the significance of the interaction term in model 3 , and this time the moderation effect is analyzed in the second way.

The level of moderating variables in Table 10 corresponds to the three lines in Figure 6. The three levels of the moderating variable are average value, high level (average value plus 1 standard deviation) and low level (average value plus minus 1 standard deviation). And the regression coefficient in Table 10 corresponds to the slope in Figure 6, which intuitively shows the difference in the influence of social norms under different emotional cognition levels. Figure 6 visualizes the difference in the magnitude (slope) of the effect of the independent variable (emotional cognition) on the dependent variable (AVA) at different levels of the moderating variable (social norms), i.e., the specific moderating effect.

Table 10. Simple slope analysis (independent variable: emotional cognition)

\begin{tabular}{|l|c|c|c|r|r|r|}
\hline $\begin{array}{c}\text { Adjustment of Variable } \\
\text { Levels }\end{array}$ & $\begin{array}{c}\text { Regression } \\
\text { Coefficient }\end{array}$ & $\begin{array}{c}\text { Standard } \\
\text { Error }\end{array}$ & \multicolumn{1}{|c|}{ T } & \multicolumn{2}{|c|}{ P } & \multicolumn{2}{|c|}{$95 \%$ CI } \\
\hline Average Value & 0.622 & 0.032 & 19.686 & 0.000 & 0.560 & 0.684 \\
\hline High Level (+1SD) & 0.759 & 0.040 & 18.828 & 0.000 & 0.680 & 0.838 \\
\hline Low Level (-1SD) & 0.486 & 0.044 & 10.946 & 0.000 & 0.399 & 0.573 \\
\hline \multicolumn{7}{|l}{ Notes: Independent Variable: Affective Perceptions. } \\
\hline
\end{tabular}

\section{DISCUSSIONS}

Currently, study on the artificial intelligence virtual assistants is still in its infancy. This research is piecemeal, focusing more on artificial intelligence products with humanoid entities. Therefore, we establish AVA model based on the technology acceptance model and the service robot acceptance model, expands the theoretical boundary of the current acceptance models. Existing theories mainly 
focus on functional attributes but fail to explore the unique empathic characteristics and social extensibility of artificial intelligence technology. we not only explore its functional cognition but also explore the emotional relationship and external social factors under the effect of empathy. This is used to get a fuller picture of how well it is received by users. The new model has a high predictive ability for AVA and can explain the differences in its causes.

First, we investigate the user's perceptions by dividing them into two categories (functional cognition and emotional cognition). In the study on functional cognition, we cut through the motivational perspective, which is different from the existing literature (Heerink et al., 2010) that focuses on technical goals. In terms of user motivation, functional cognition (perceived usefulness and perceived of ease of use) reflects the user's assessment of benefits and costs, respectively, which in turn drives the motivation to use and ultimately leads to a change in AVA. According to Rauschnabel et al. (2018), they generalize user needs, including utilitarian benefits, hedonic benefits, and symbolic benefits. Users often use an AI virtual assistant to collect information to complete a task, so functional cognition represents the utilitarian interests of users. In this time, perceived usefulness represents an assessment of gains, and perceived of ease of use represents an assessment of labor expenditures. This research confirms the following through the empirical study. Also, this research confirms that functional cognition has a significant positive relationship with AVA and plays a key role in improving AVA.

Meanwhile, we examine the effect of emotional cognition on AVA. Emotional cognition includes perceived social presence, perceived social interactions, and perceived humanness. The empirical test shows that perceived social presence, perceived social interactivity all contribute to AVA. Where social presence prompts users to escalate their perceptual presence and social interactions, the perceived social presence and perceived social interactivity help to increase AVA. In addition, the findings on perceived humanness show a non-linear relationship with AVA, which differs from the hypothesized positive correlation view, like the theoretical disagreement that exists in previous studies. The existing divergent situation has been consolidated into two basic categories: one part of the research argues that perceived humanness positively facilitates the acceptance process (Gursoy et al., 2019; Schuetzler et al., 2018; Qiu \& Benbasat, 2009); the other part of the research argues that perceived humanness's positive facilitation effect does not apply to AI devices (Mimoun et al., 2012; Garnier \& Poncin, 2013), but instead challenges customers' perceptions of humanness's uniqueness and self-identification (Ackerman, 2016). To address existing disagreements, this research draws on psychological theories related to the "Eliza Effect"' (Kim et al., 2019). Perceived humanness is related to the AI virtual assistant's psychological characteristics (emotions, personality, etc.) like human beings. Perceived humanness enhances the user's sense of familiarity and psychological warmth, which promotes AVA. But, when the AI virtual assistants are very close to humans, users tend to have negative attitudes. This phenomenon is known as the "Eliza Effect" (Kim et al., 2019). As the AI virtual assistants become more and more humane, users will perceive it as unnatural or even frightening due to the "Eliza Effect". At this point, the perceived humanness is too high, leading to the decrease of AVA (Doorn et al., 2017). It explains that there is a nonlinear inverted U-shaped relationship between perceived humanness and AVA, which echoes the existing nonlinear research results.

Finally, this research investigates the influence of social norms to different degrees. We explain the deepening effect of social norms on functional cognition and emotional cognition through social impact theory, respectively, and verify the significant positive moderating effect of social norms through empirical data. The interaction between the user and the AI constitutes a special learning process (Chad Edwards et al., 2018). In the process of learning, the influence of social norms makes users' perceptions of use present the position favored by their group, to maintain group harmony. The research argues that the influence of social norms is a kind of perceived pressure from society, which strengthens the degree to which users make a certain decision. As suggested by Lee et al. (2011), information from others is only complementary. In other words, users may or may not follow the recommendations. Social norms change the existing acceptance intention by adjusting the influence 
of user cognition on AVA. Therefore, social norms regulate the influence of functional and emotional cognition on AVA, rather than the direct influence on the intention to receive.

At present, the dark side of the application of artificial intelligence technology has aroused a lot of discussions. The black-box process of artificial intelligence and the opacity of machine learning also raise social considerations. In this research, the influence framework of social norms is introduced into AVA model, and the social theory is combined with the theory of artificial intelligence technology to confirm the regulation mechanism of social norms on AVA. Similarly, it helps promote products such as artificial intelligence virtual assistants. It also helps to provide a theoretical basis for addressing social-ethical issues related to these products, such as existing prejudice and mistrust. Due to the progress of artificial intelligence technology, social trends and trends of artificial intelligence products may be formed in the future. Users use artificial intelligence to work, conform to group trends and make themselves more important in social groups. At the same time, the artificial intelligence virtual assistants are forming a new social model with users. Social norms play an important role in this binary interaction. The theoretical innovation of this research has important reference significance for the functional design of future artificial intelligence virtual assistants, meeting the needs of users, and building a unique artificial intelligence interactive community.

\section{LIMITATIONS AND FUTURE RESEARCH DIRECTIONS}

The model of the research reveals the important influence of user cognition and community norms on the artificial intelligence virtual assistants. The results of this study provide a useful reference for establishing an effective model to motivate users' acceptance behaviors of the artificial intelligence virtual assistants. These results are useful for developers of the artificial intelligence virtual assistants and practitioners of artificial intelligence technologies. However, like most empirical studies, this study is not without its limitations.

First, the current user-centered empirical research usually adopts the classical framework (e.g., the technology acceptance model, the service robot acceptance model). Although these models are combined in this research, there are still limitations. The application of these models is often limited to a single type of product, which may be limited. Second, the data in this research is mainly collected using samples from the surrounding population, so there may be limitations in generalizing the results. Given the wide range of use of the artificial intelligence virtual assistants in the future, future research should address relevant issues through a broader and larger sample. Finally, the models in this study refer to the technology acceptance model and the service robot acceptance model, including functional cognition and emotional cognition. However, other studies also focus on hedonic factors, trust factors, and other driving factors. Further validation is needed in the future to expand the boundaries of theoretical models and explore the regulatory mechanism of social norms on hedonic factors and trust factors. In addition, the discussion of the regulation mechanism of social norms in this research mainly focuses on different levels of social norms, and less attention is paid to the differences brought by different sources of social norms. Future research can further classify social norms from different sources and explore their differences. 


\section{REFERENCES}

A, O. F., \& B, M. L. (2018). Examining online social brand engagement: a social presence theory perspective. Technological Forecasting and Social Change, 128, 10-21.

A, R. M. S., B, J. S. G., C, G. M. G., \& D, J. F. N. (2018). The influence of conversational agent embodiment and conversational relevance on socially desirable responding - ScienceDirect. Decision Support Systems, 114, 94-102.

Ackerman, E. (2016). Study: Nobody wants social robots that look like humans because they threaten our identity. IEEE Spectrum, 1-5.

Breazeal, C. (2013). Toward sociable robots. Robotics and Autonomous Systems, 42, 167-175.

Chattaraman, V., Kwon, W., Gilbert, J., \& Ross, K. (2019). Should AI-Based, conversational digital assistants employ social-or task-oriented interaction style? A task- competency and reciprocity perspective for older adults. Computers in Human Behavior, 90, 315-330. doi:10.1016/j.chb.2018.08.048

Compeau, D., Higgins, C. A., \& Huff, S. (1999). Social cognitive theory and individual reactions to computing technology: A longitudinal study. Management Information Systems Quarterly, 23(2), 145-158. doi:10.2307/249749

Davis, F. D. (1989). Perceived Usefulness, Perceived Ease of Use, and User Acceptance of Information Technology. Management Information Systems Quarterly, 13(3), 319-340. doi:10.2307/249008

Davis, F. D., Bagozzi, R. P., \& Warshaw, P. R. (1989). User Acceptance of Computer Technology: A Comparison of Two Theoretical Models. Management Science, 35(8), 982-1003. doi:10.1287/mnsc.35.8.982

Davis, F. D., Bagozzi, R. P., \& Warshaw, P. R. (1992). Extrinsic and Intrinsic Motivation to Use Computers in the Workplace. Journal of Applied Social Psychology, 22(14), 1111-1132. doi:10.1111/j.1559-1816.1992.tb00945.x

Doorn, V. (2017). Domo Arigato Mr. Roboto: Emergence of automated social presence in organizational frontlines and customers' service experiences. Journal of Service Research, 20(1), 43-58. doi:10.1177/1094670516679272

Edwards, C., Edwards, A., Stoll, B., Lin, X., \& Massey, N. (2018). Evaluations of an artificial intelligence instructor's voice: Social identity theory in human-robot interactions. Computers in Human Behavior, 90.

Fernandes, T., \& Oliveira, E. (2021). Understanding consumers' acceptance of automated technologies in service encounters: Drivers of digital voice assistant's adoption. Journal of Business Research, 122, 180-191. doi:10.1016/j.jbusres.2020.08.058

Festinger, L. (1957). A Theory of Cognitive Dissonance. Row \& Peterson.

Garnier, M., \& Poncin, I. (2013). The avatar in marketing: Synthesis, integrative framework and perspectives. Recherche et Applications en Marketing, 28(1), 85-115. doi:10.1177/2051570713478335

Gursoy, D., Chi, O. H., Lu, L., \& Nunkoo, R. (2019). Consumers acceptance of artificially intelligent (AI) device use in service delivery. International Journal of Information Management, 49, 157-169. doi:10.1016/j. ijinfomgt.2019.03.008

Hassanein, K., \& Head, M. (2007). Manipulating perceived social presence through the web interface and its impact on attitude towards online shopping. International Journal of Human-Computer Studies, 65(8), 689-708. doi:10.1016/j.jhcs.2006.11.018

Heerink, M., Krose, B., Evers, V., \& Wielinga, B. (2008). The influence of social presence on acceptance of a companion robot by older people. Journal of Physical Agents, 2(2), 33-40.

Heerink, M., Kröse, B., Evers, V., \& Wielinga, B. (2010). Relating conversational expressiveness to social presence and acceptance of an assistive social robot. Virtual Reality (Waltham Cross), 14(1), 77-84. doi:10.1007/ s10055-009-0142-1

Jeon, M. M., Lee, S., \& Jeong, M. (2018). e-Social influence and customers' behavioral intentions on a bed and breakfast website. Journal of Hospitality Marketing \& Management, 27(3), 366-385. doi:10.1080/19368 623.2017 .1367346 
Kim, S. Y., Schmitt, B. H., \& Thalmann, N. M. (2019). Eliza in the uncanny valley: Anthropomorphizing consumer robots increases their perceived warmth but decreases liking. Marketing Letters, 30(1), 1-12. doi:10.1007/ s11002-019-09485-9

Kulviwat, S., Bruner, G. C. II, Kumar, A., Nasco, S. A., \& Clark, T. (2007). Toward a unified theory of consumer acceptance technology. Psychology and Marketing, 24(12), 1059-1084. doi:10.1002/mar.20196

Latané, B. (1981). The Psychology of Social Impact. The American Psychologist, 36, 343. doi:10.1037/0003066X.36.4.343

Law, R., Chan, I. C. C., \& Wang, L. (2018). A comprehensive review of mobile technology use in hospitality and tourism. Journal of Hospitality Marketing \& Management, 27(6), 626-648. doi:10.1080/19368623.2018.1423251

Lazarus, R. S. (1991). Emotion and Adaptation. Oxford University Press.

Lee, M. K. O., Cheung, C. M. K., Sia, C. L., \& Lim, K. H. (2006). How positive informational social influence affects consumers' decision of internet shopping? In Proceedings of the 39th Hawaii international conference on system sciences, Paper 115. doi:10.1109/HICSS.2006.204

Lee, Y., Kozar, K. A., \& Larsen, K. R. (2003). The technology acceptance model: Past, present, and future. Communications of the Association for Information Systems, 12(1), 50. doi:10.17705/1CAIS.01250

Lin, H., Chi, O. H., \& Gursoy, D. (2019). Antecedents of customers' acceptance of artificially intelligent robotic device use in hospitality services. Journal of Hospitality Marketing \& Management, 29(5), 530-549. doi:10.1 080/19368623.2020.1685053

Lu, V. N., Wirtz, J., Kunz, W. H., Paluch, S., \& Patterson, P. G. (2020). Service robots, customers, and service employees: What can the authors learn from the academic literature and where are the gaps? Journal of Service Theory and Practice, 30(3), 361-391. doi:10.1108/JSTP-04-2019-0088

Mclean, G., \& Wilson, A. (2019). Shopping in the digital world: Examining customer engagement through augmented reality mobile applications. Computers in Human Behavior, 101, 101. doi:10.1016/j.chb.2019.07.002

Mimoun, M. S. B., Poncin, I., \& Garnier, M. (2012). Case study embodied virtual agents: An analysis on reasons for failure. Journal of Retailing and Consumer Services, 19(6), 605-612. doi:10.1016/j.jretconser.2012.07.006

Nass, C. I., \& Moon, Y. (2000). Machines and mindlessness: Social responses to computers. The Journal of Social Issues, 56(1), 81-103. doi:10.1111/0022-4537.00153

Nass, C. I., Moon, Y., \& Green, N. (2010). Are machines gender neutral? gender-stereotypic responses to computers with voices. Journal of Applied Social Psychology, 27(10), 864-876. doi:10.1111/j.1559-1816.1997. tb00275.x

Ng, C. Y., Law, K. M., \& Ip, A. W. (2021). Assessing Public Opinions of Products Through Sentiment Analysis: Product Satisfaction Assessment by Sentiment Analysis. Journal of Organizational and End User Computing, 33(4), 125-141. doi:10.4018/JOEUC.20210701.oa6

Ostrom, A. L., Fotheringham, D., \& Bitner, M. J. (2019). Customer acceptance of AI in service encounters: understanding antecedents and consequences. In Handbook of Service Science (Vol. 2, pp. 77-103). Springer. doi:10.1007/978-3-319-98512-1_5

Pelau, C., Dabija, D.-C., \& Ene, I. (2021). What makes an AI device human-like? The role of interaction quality, empathy, and perceived psychological anthropomorphic characteristics in the acceptance of artificial intelligence in the service industry. Computers in Human Behavior, 122.

Qiu, H., Li, M., Shu, B., \& Bai, B. (2020). Enhancing hospitality experience with service robots: The mediating role of rapport building. Journal of Hospitality Marketing \& Management, 29(3), 247-268. doi:10.1080/1936 8623.2019.1645073

Qiu, L., \& Benbasat, I. (2009). Evaluating anthropomorphic product recommendation agents: A social relationship perspective to designing information systems. Journal of Management Information Systems, 25(4), 145-182. doi:10.2753/MIS0742-1222250405 
Rather, R. A. (2018). Investigating the impact of customer brand identification on hospitality brand loyalty: A social identity perspective. Journal of Hospitality Marketing \& Management, 27(5), 487-513. doi:10.1080/19 368623.2018 .1404539

Rauschnabel, P. A., He, J., \& Ro, Y. K. (2018). Antecedents to the adoption of augmented reality smart glasses: A closer look at privacy risks. Journal of Business Research, 92, 374-384. doi:10.1016/j.jbusres.2018.08.008

Reeves, B., \& Nass, C. (1996). The media equation: how people treat computers, television, and new media like real people and places. Cambridge University Press.

Sohn, K., \& Kwon, O. (n.d.). Technology acceptance theories and factors influencing artificial intelligence-based intelligent products. Telematics and Informatics, 47.

Thompson, R. L., Higgins, C. A., \& Howell, J. M. (1991). Personal computing: Toward a conceptual model of utilization. Management Information Systems Quarterly, 15(1), 125-143. doi:10.2307/249443

Tinwell, A., Grimshaw, M., Nabi, D., \& Williams, A. (2011). Facial expression of emotion and perception of the Uncanny Valley in virtual characters. Computers in Human Behavior, 27(2), 741-749. doi:10.1016/j. chb.2010.10.018

Uddin, M. A., Mahmood, M., Ostrovskiy, A., \& Hwang, H. J. (2021). Can Social Networks Improve User Subjective Wellbeing? Role of Passion and Personality Traits. Journal of Global Information Management, 29(4), 53-77. doi:10.4018/JGIM.20210701.oa3

Vedadi, A., \& Greer, T. H. (2021). Revisiting How Perceived Uncertainty and Herd Behavior Influence Technology Choice. Journal of Organizational and End User Computing, 33(6), 1-19. doi:10.4018/JOEUC.20211101.oa1

Velez, J. E., \& Jentsch, F. (2016). Robot Emotive Display Systems and the Analogous Physical Features of Emotion. Proceedings of the Human Factors and Ergonomics Society Annual Meeting, 60(1), 1344-1348. doi:10.1177/1541931213601310

Venkatesh, V. (2000). Determinants of perceived of ease of use: Integrating control, intrinsic motivation, and emotion into the technology acceptance model. Information Systems Research, 11(4), 342-365. doi:10.1287/ isre.11.4.342.11872

Venkatesh, V., Morris, M. G., Davis, G. B., \& Davis, F. D. (2003). User acceptance of information technology: Toward a unified view. Management Information Systems Quarterly, 27(3), 425-478. doi:10.2307/30036540

Wang, X. W., Riaz, M., Haider, S., \& Alam, K. M., \& Yang, M. (2021). Information Sharing on Social Media by Multicultural Individuals: Experiential, Motivational, and Network Factors. Journal of Global Information Management, 29(6), 1-24.

Wirtz, J., Patterson, P. G., Kunz, W. H., Gruber, T., Lu, V. N., Paluch, S., \& Martins, A. (2018). Brave new world: Service robots in the frontline. Journal of Service Management, 29(5), 907-931. doi:10.1108/JOSM04-2018-0119

Yoo, J., Choi, S., Hwang, Y., \& Yi, M. Y. (2021). The Role of User Resistance and Social Influences on the Adoption of Smartphone: Moderating Effect of Age. Journal of Organizational and End User Computing, 33(2), 36-58. doi:10.4018/JOEUC.20210301.oa3 
Xiaomin Du is a Lecturer in Department of Economic Management at Yingkou Institute of Technology in China. She received the Ph.D. degree in management science and engineering from Jilin University, China. She has researched in the field of operation management and business model for 8 years. As a research author, she has published many academic papers. She is also the reviewers of several international journals.

Xinran Zhao is a researcher with Professor Gao Yang at the Business School of Dalian University of Technology, China. Her research interests are big data and artificial intelligence.

Chia-Huei Wu, corresponding author, is currently an Associate Professor at Department of Hotel Management and Culinary Creativity, Minghsin University of Science and Technology in Taiwan. 